\title{
Pteleopsis suberosa Engl. and Diels (Combretaceae) aqueous stem bark extract extenuates oxidative damage in streptozotocin-induced diabetic Wistar rats
}

\author{
Aladodo Abimbola Raliat' ${ }^{2}$, Sabiu Saheed ${ }^{1, *}$, Sulyman Olarewaju Abdulhakeem ${ }^{2}$
}

\section{Aladodo Abimbola Raliat ${ }^{2}$, Sabiu Saheed ${ }^{1, *}$, Sulyman Olarewaju Abdulhakeem²

\author{
'Department of Microbial, Biochemical \\ and Food Biotechnology, University \\ of the Free State, P.O. Box 339, Nelson \\ Mandela Drive, 9301 Bloemfontein, \\ SOUTH AFRICA. \\ ${ }^{2}$ Department of Medical Biochemistry \\ and Pharmacology, School of Basic \\ Medical Sciences, Kwara State University, \\ Malete. P.M.B. 1530, Ilorin, NIGERIA. \\ Correspondence \\ Dr. Sabiu S
}

Department of Microbial, Biochemical and Food Biotechnology, University of the Free State, P.O. Box 339, Nelson Mandela Drive, 9301 Bloemfontein, SOUTH AFRICA.

Phone no : +27631935745

E-mail: saeed.sabiu@gmail.com

\section{History}

- Submission Date: 15-07-2018;

- Review completed: 21-09-2018;

- Accepted Date: 13-12-2018

DOI : 10.5530/pj.2019.1.30

Article Available online http://www.phcogj.com/v11/i1

\section{Copyright}

(C) 2019 Phcog.Net. This is an openaccess article distributed under the terms of the Creative Commons Attribution 4.0 International license.

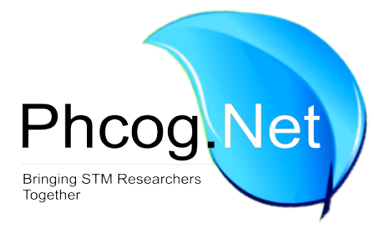

\begin{abstract}
Context: Pteleopsis suberosa Engl. and Diels (Combretaceae) is an ethnomedicinally valued deciduous shrub with significant therapeutic application against diabetes in West Africa. Aims: This study evaluated the hypoglycaemic and antioxidant activity of its aqueous stem bark extract (PSAE) over a 15-day experimental period in streptozotocin (STZ)-challenged diabetic rats. Methods and Material: STZ-induced diabetic rats were administered 50, 100 and $200 \mathrm{mg} / \mathrm{kg}$ body weight of the extract once daily and the blood glucose levels were monitored for 15 days. The bioactive constituents of PSAE were analyzed using Gas Chromatography-Mass Spectrometry (GC-MS) technique. Results: Treatment with PSAE markedly $(p<0.05)$ ameliorated the concentrations of blood glucose and improved the lipid metabolism imbalance in the diabetic animals. Also, while PSAE significantly $(p<0.05)$ improved glycogen and glutathione (reduced) levels as well as glucose-6-phosphate dehydrogenase, superoxide dismutase and catalase activities, the concentrations of glucose and malondialdehyde coupled with the activity of $\alpha$-amylase were significantly reduced in the liver of PSAE-administered diabetic animals when compared with those of the normal control and untreated diabetic groups. The observed improvements could be associated with the phytoconstituents of PSAE as evident from the results of the GC-MS analysis. Put together, the elicited effects compared favorably well with metformin (a standard hypoglycemic drug) and are suggestive of antidiabetic and antioxidant capabilities of the extract. Conclusion: The scope of the data presented in this study indicates that the extract ameliorated streptozotocin-induced diabetes in rats and it is suggested to be mediated via antioxidant and concerted blood glucose lowering actions. Key words: Antioxidant, Arjunglycoside, Diabetes, Glucose-6-phosphate dehydrogenase, Hyperglycaemia, Pteleopsis suberosa.

Key Messages: Pteleopsis suberosa potentiates significant antioxidant and concerted blood glucose lowering actions. Such properties ultimately present $P$. suberosa as a promising new lead that could be harnessed as functional food and in the development of oral hypoglycaemic drugs.
\end{abstract}

\section{INTRODUCTION}

Pteleopsis suberosa Engl. and Diels (Combretaceae) is a deciduous shrub, 6-10 $\mathrm{m}$ tall with characteristic bark distinctively covered with corky warts. It occurs freely in West Africa, from Senegal east to Nigeria. The different parts of P. suberosa (PS) have been medicinally used throughout West Africa. A decoction of the fresh roots is normally applied as enema, purgative, antidysentery and to treat dermatitis, stomach ache and gastric ulcers. ${ }^{1}$ Its roots and young shoots extracts are taken as antituisive. The bark or leafy twig infusion of PS is also ethnomedicinally valued to treat jaundice, toothache, haemorrhoids, filariasis, wounds, conjunctivitis, trachoma, cataract and as aphrodisiac., ${ }^{2,3}$ It has also been reported to be rich in triterpenoids, coumarins and tannins as its essential phytonutrients. ${ }^{4}$
The upsurge in the prevalence of diabetes mellitus (DM) has remained a significant health challenge with marked economic burden. ${ }^{5,6}$ While $\mathrm{DM}$ is already a prominent and well known disease in industrialized nations, its status and occurrence in the developing countries is also alarming, with the type 2 form accounting for more than $90 \%$ of reported cases. ${ }^{7,8}$ With this report, more than 552 million individuals of the global population are estimated to be diabetic by the year 2030, if no suitable alternative is in place. ${ }^{9,10}$ The effectiveness of orthodox management of DM through the use of oral hypoglycemic drugs is undoubtable, however factors such as high cost and significant side effects have undermined their application till date. Accordingly, emerging evidence-based research focused on 
diabetes care are now exploring more affordable and easily accessible natural herbal preparations. ${ }^{11,12}$ Such studies are not only envisioned to advance the path for a new therapeutic strategy for diabetes treatment and its related complications, ${ }^{13,14}$ but also offer safer and more affordable adaptogenic bioactive agents that will improve the quality of life of diabetic patients. ${ }^{15}$ Interestingly, the results of many ethnobotanical surveys of the antidiabetic medicinal plants in West Africa, particularly from Togo, ${ }^{16}$ Oyo State, Nigeria ${ }^{17}$ and Cotonou, Benin Republic, ${ }^{18}$ revealed the roots, leaf and stem barks of PS as a prominently employed herb in the treatment of DM. In spite of these reports, the scientific validation of the hypoglycaemic potentials of PS is still lacking in literatures till date. It is on this background, that the present study investigates its antidiabetic potential in vivo. The analysis of its adaptogenic constituents and antioxidant potentials were also conducted.

\section{MATERIALS AND METHODS \\ Drugs, reagents, assay kits and chemicals}

Streptozotocin (STZ) and metformin were products of Qianjin Pharmaceutical Company Limited, China and Santa Cruz Biotechnology, Germany, respectively. While potassium ferricyanide $\left(\mathrm{K}_{3} \mathrm{Fe}(\mathrm{CN})_{6}\right)$, 2,2-diphenyl-1-picrylhydrazyl (DPPH), vitamin C, trichloroacetic acid, phosphate buffer and sucrose were supplied by Sigma-Adrich Company, Missouri, USA, all the assay kits (except otherwise stated) including those for the determination of high-density lipoprotein cholesterol (HDL-C), low-density lipoprotein cholesterol (LDL-C), total cholesterol (TC) and triacylglycerides (TG) were purchased from Randox Laboratory Limited, United Kingdom. All the other reagents and chemicals used were of analytical standard.

\section{Sample collection, identification and extraction}

The stem barks of $P$. suberosa used in this study were taken from a farm in Malete, Kwara State, Nigeria, in January, 2016 and authenticated (voucher number UIH 001/1213) by Mr. Bolu Ajayi.

The barks were thoroughly rinsed with distilled $\mathrm{H}_{2} \mathrm{O}$ prior to pulverization. Subsequently, a portion (500 g) of the powdered sample was extracted with distilled $\mathrm{H}_{2} \mathrm{O}(5 \mathrm{~L})$ with regular shaking for 2 days. Using Whatman No. 1 filter paper, the obtained mixture was filtered and the filtrate lyophilized. The extract obtained (PSAE) was kept air-tight at $4^{\circ} \mathrm{C}$ before use.

\section{Animals used}

The adult male Wistar strain rats (weight 150-200 g) used in this study were obtained from the Experimental Animal House Unit of University of Ilorin, Nigeria. They were acclimatized for 2 weeks in a well-ventilated house with optimum conditions (humidity of $45-50 \%$, photoperiod of $12 \mathrm{~h}$ light and $12 \mathrm{~h}$ dark cycle and a temperature of $23 \pm 1^{\circ} \mathrm{C}$ ) and had ad libitum access to feed and potable water. The overall experimental protocols were reviewed and certified by the Department of Medical Biochemistry and Pharmacology, Kwara State University, Nigeria in accordance with National Institute of Health for the Care and Use of Laboratory Animals (\#85-23) ${ }^{19}$ and National Research Council Guide. ${ }^{20}$

\section{Diabetes induction}

This was done adopting the method of Bell and Jr. Hye. ${ }^{21}$ Briefly, the rats were fasted overnight prior to a single dose $(65 \mathrm{mg} / \mathrm{kg}$ b.w.) of STZ in citrate buffer $(0.01 \mathrm{M}, \mathrm{pH} 4.5)$ intraperitoneally administered. Using a glucose oxidase-based glucometer (Accu-Chek, Roche Products (Pty) Ltd., South Africa), the blood glucose of each animal before induction and after $48 \mathrm{~h}$ was determined. Animals having blood glucose of at least $250 \mathrm{mg} / \mathrm{dL}$ after $48 \mathrm{~h}$ and had hyperglycemia for the next 3 days with characteristic behavioral changes such as excess thirst and frequent urination were considered diabetic and recruited for the study. At the time of induction, control rats were injected with citrate buffer $(0.5 \mathrm{~mL})$ alone.

\section{Experimental protocol}

The thirty rats recruited for the study were randomized into six groups of five animals each. The normal control (Group 1) and Group 2 (diabetic control) animals received $1.0 \mathrm{~mL}$ each of distilled $\mathrm{H}_{2} \mathrm{O}$. Group 3 comprised diabetic animals treated with metformin ( $14.2 \mathrm{mg} / \mathrm{kg}$ b.w.), while animals in Groups 4 to 6 are diabetic rats respectively administered $1.0 \mathrm{~m} \mathrm{~L}$ each of 50, 100 and $200 \mathrm{mg} / \mathrm{kg}$ b.w. of PSAE. Administrations were orally performed daily and lasted for 15 days.

The chosen doses (50-200 mg/kg b.w.) in this study were primed by the results of the survey on the use of PS in diabetes care and the initial evaluation of its maximum safe and minimum effective doses. ${ }^{22}$

On the $15^{\text {th }}$ day, the animals were humanely anaesthetized and blood (2.0 $\mathrm{mL}$ and $5.0 \mathrm{~mL}$ respectively) was collected into EDTA-coated tubes and plane tubes for lipid profile and biochemical analyses. The animals were also quickly dissected and the liver removed, cleaned, homogenized [Tris- $\mathrm{HCl}$ buffer ( $\mathrm{pH} 7.4$ ) containing $1.15 \% \mathrm{KCl}$ and $0.05 \mathrm{M}$ Tris-HCl] and subsequently used for hepatic glycaemic indices and antioxidant analyses.

\section{Biochemical assays \\ Estimation/monitoring of blood glucose level and lipid profiles}

At every other day throughout the experimental period and subsequent to a 12-h fast, sample of blood was taken from the caudal vein of the rats and used to determine their blood glucose level (glucometer).

The serum lipid profiles (HDL-C, LDL-C, TC, TG and TC) were evaluated as per the manufacturer's instructions in the kits.

\section{Determination of glucose, glycogen and enzyme activities in the liver homogenate}

The level of glycogen content was estimated as earlier reported, ${ }^{23}$ while the units of glucosyl were enzymatically evaluated. ${ }^{24}$ The glucose-6-phosphate dehydrogenase $(\mathrm{G} 6 \mathrm{PDH})$ and $\alpha$-amylase activities were respectively evaluated as described by Lohr and Waller ${ }^{25}$ and McCue et al. ${ }^{26}$

\section{Determination of hepatic antioxidant status}

While the level of lipid peroxidation in terms of malondialdehyde (MDA) was estimated as earlier described, ${ }^{27}$ the respective tissue activities of enzymic antioxidants [catalase (CAT) and superoxide dismutase (SOD)] and the reduced glutathione (GSH) level were evaluated adopting the procedures of Aebi, ${ }^{28}$ Marklund and Marklund, ${ }^{29}$ and Ellman. ${ }^{30}$

\section{In vitro antioxidant assays}

Using the methods of Oyaizu, ${ }^{31}$ Ruch et al. ${ }^{32}$ and Turkoglu et al. ${ }^{33}$ the reducing power capability as well as the $\mathrm{H}_{2} \mathrm{O}_{2}$ and DPPH radicals scavenging potentials of PSAE were evaluated respectively.

\section{Phytoconstituent analysis of PSAE using GC-MS}

The Agilent Technologies GC systems with GC-7890A/MS-5975C model (Agilent Technologies, Santa Clara, CA, USA) equipped with HP-5MS column $(30 \mathrm{~m}$ in length $\times 250 \mu \mathrm{m}$ in diameter $\times 0.25 \mu \mathrm{m}$ in thickness of film) was used in the analysis. The concentration of the individual constituent in PSAE was presented as \% on the basis of the peak area in the chromatogram. For their identification, matching of their characteristic features with the different components in the NIST library was used. 


\section{Statistical evaluation}

Except otherwise stated, the data were processed by one-way analysis of variance complemented with Duncan's Multiple Range Test using SPSS software package for windows V16.0. Results are represented as mean \pm standard error of the mean (SEM) of replicate determinations. At a $p<0.05$ confidence level, the values of the mean were considered statistically significant.

\section{RESULTS}

All the animals showed characteristic normal blood glucose levels prior to STZ-treatment (Figure 1). Except for the normal control group that had fairly constant normal blood glucose level, all the STZ-administered groups had significantly high blood glucose levels subsequent to induction. However, the continuous administration of PSAE for 15 days resulted in significantly $(p<0.05)$ reduced blood glucose concentration in the diabetic animals at the end of the experiment (Figure 1). It is noteworthy that, the most pronounced effects with normoglycaemic levels $(\leq 120 \mathrm{mg} / \mathrm{dL}$ ) were evident in the rats administered $100-200 \mathrm{mg} / \mathrm{kg}$ b.w. PSAE after 13 days of treatment and they compared favourably well with metformin-treated animals (Figure 1).

The data obtained on the influence of PSAE on the serum lipid profiles of the experimental rats are presented in Table 1. A significant $(p<0.05)$ rise (more than 1.5 fold) in the concentrations of LDL-C, TG and TC and reduction in HDL-C level was observed in the diabetic control animals relative to the normal control group. However, when compared with the normal control, administration of the extracts and metformin significantly $(p<0.05)$ reverted the trends in these lipid parameters to near normalcy (Table 1 ).

The effects of PSAE treatments on the glucose and glycogen contents in the liver as well as the activities of $\alpha$-amylase and G6PDH of STZ-challenged animals are shown in Table 2. Compared with the normal control animals, there was a significant $(p<0.05)$ increase in the hepatic glucose concentration of the diabetic control animals, while the glycogen content decreased significantly. The observed elevation in the glucose level was however significantly ameliorated following the 15-day treatment with PSAE. While PSAE at $50 \mathrm{mg} / \mathrm{kg}$ b.w. dose elicited glucose lowering effect that compared well with metformin, those of the higher doses had values comparable to the normal control rats. The reduced glycogen contents in the diabetic control rats were also increased concentration-dependently in the extract-treated rats with the $200 \mathrm{mg} \cdot \mathrm{kg}^{-1}$ dose eliciting the

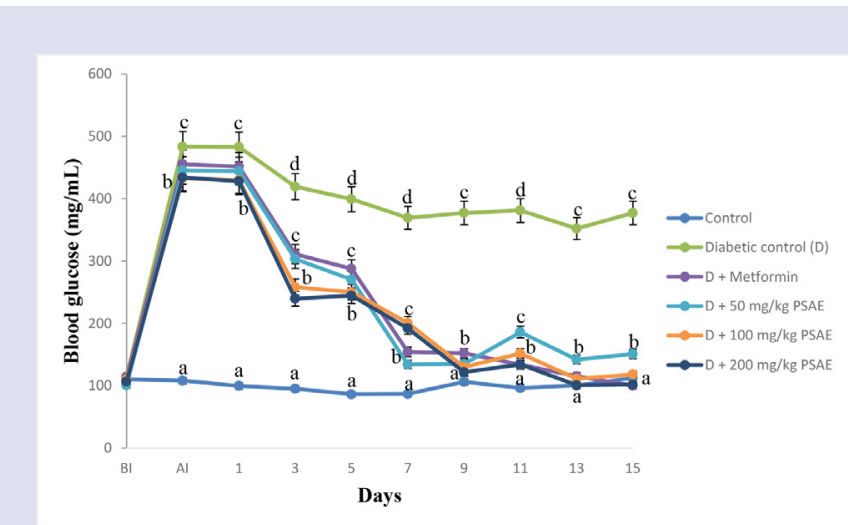

Figure 1: Effect of oral administration of aqueous stem bark extract of P. suberosa on blood glucose levels in diabetic rats $(n=5$, mean \pm SEM). $\mathrm{Bl}=$ Before induction, $\mathrm{Al}=$ After induction
Table 1: Effect of oral administration of aqueous stem bark extract of $P$. suberosa on serum lipid profile $(\mathrm{mg} / \mathrm{dL})$ in diabetic rats.

\begin{tabular}{ccccc}
\hline Treatments & LDL-C & HDL-C & TG & TC \\
\hline Normal control & $32.50 \pm$ & $13.62 \pm$ & $106.33 \pm$ & $50.21 \pm$ \\
& $1.03^{\mathrm{a}}$ & $0.36^{\mathrm{a}}$ & $0.67^{\mathrm{a}}$ & $0.80^{\mathrm{a}}$ \\
Diabetic control (DA) & $60.01 \pm$ & $8.03 \pm$ & $303.11 \pm$ & $87.32 \pm$ \\
& $1.10^{\mathrm{b}}$ & $0.45^{\mathrm{b}}$ & $0.23^{\mathrm{b}}$ & $0.11^{\mathrm{b}}$ \\
DA + Met. (14.2 mg/kg b.w.) & $38.23 \pm$ & $15.82 \pm$ & $203.61 \pm$ & $53.33 \pm$ \\
& $0.99^{\mathrm{c}}$ & $0.35^{\mathrm{c}}$ & $0.44^{\mathrm{c}}$ & $0.25^{\mathrm{a}}$ \\
DA + 50 mg/kg b.w. extract & $36.25 \pm$ & $14.21 \pm$ & $220.11 \pm$ & $59.67 \pm$ \\
& $0.86^{\mathrm{c}}$ & $0.17^{\mathrm{c}}$ & $0.67^{\mathrm{c}}$ & $0.65^{\mathrm{c}}$ \\
DA + $100 \mathrm{mg} / \mathrm{kg}$ b.w. extract & $35.32 \pm$ & $14.99 \pm$ & $139.62 \pm$ & $51.77 \pm$ \\
& $1.11^{\mathrm{c}}$ & $0.22^{\mathrm{c}}$ & $0.12^{\mathrm{d}}$ & $0.24^{\mathrm{a}}$ \\
DA + $200 \mathrm{mg} / \mathrm{kg}$ b.w. extract & $33.01 \pm$ & $15.01 \pm$ & $101.32 \pm$ & $50.70 \pm$ \\
& $0.62^{\mathrm{a}}$ & $0.72^{\mathrm{c}}$ & $0.18^{\mathrm{a}}$ & $0.66^{\mathrm{a}}$ \\
\hline
\end{tabular}

$(\mathrm{n}=5$, mean \pm SEM). abcd Values with different superscripts along the same column for each parameter are significantly different $(\mathrm{P}<0.05)$. DA; diabetic animal

Table 2: Effect of oral administration of aqueous stem bark extract of $P$. suberosa on hepatic levels $(\mathrm{mg} / \mathrm{g}$ ) of glucose and glycogen and specific activities ( $\mathrm{nm} / \mathrm{min} / \mathrm{mg}$ protein) of $\alpha$-amylase and G6PDH in diabetic rats.

\begin{tabular}{ccccc}
\hline Treatments & Glucose & Glycogen & a-amylase & G6PDH \\
\hline Normal control & $16.00 \pm$ & $13.16 \pm$ & $13.34 \pm$ & $350.94 \pm$ \\
& $0.99^{\mathrm{a}}$ & $0.77^{\mathrm{a}}$ & $0.01^{\mathrm{a}}$ & $3.66^{\mathrm{a}}$ \\
Diabetic control (DA) & $34.87 \pm$ & $6.21 \pm$ & $25.74 \pm$ & $20.80 \pm$ \\
& $0.23^{\mathrm{b}}$ & $0.11^{\mathrm{b}}$ & $0.03^{\mathrm{b}}$ & $1.09^{\mathrm{b}}$ \\
DA + Met. & $18.89 \pm$ & $12.82^{\mathrm{a}} \pm$ & $13.57 \pm$ & $182.96 \pm$ \\
(14.2 $\mathrm{mg} / \mathrm{kg}$ b.w.) & $0.32^{\mathrm{c}}$ & $0.62^{\mathrm{a}}$ & $0.02^{\mathrm{a}}$ & $2.01^{\mathrm{c}}$ \\
DA + $50 \mathrm{mg} / \mathrm{kg}$ b.w. & $18.41 \pm$ & $11.33 \pm$ & $12.93 \pm$ & $82.24 \pm$ \\
extract & $0.21^{\mathrm{c}}$ & $0.15^{\mathrm{c}}$ & $0.01^{\mathrm{a}}$ & $1.89^{\mathrm{d}}$ \\
DA + 100 mg/kg b.w. & $15.05 \pm$ & $11.80 \pm$ & $16.33 \pm$ & $113.81 \pm$ \\
extract & $0.10^{\mathrm{a}}$ & $0.35^{\mathrm{c}}$ & $0.07^{\mathrm{c}}$ & $2.80^{\mathrm{e}}$ \\
DA + 200 mg/kg b.w. & $15.09 \pm$ & $13.34 \pm$ & $15.80 \pm$ & 180.03 \\
extract & $0.11^{\mathrm{a}}$ & $0.15^{\mathrm{a}}$ & $0.06^{\mathrm{c}}$ & $\pm 1.99^{\mathrm{c}}$ \\
\hline
\end{tabular}

$\left(\mathrm{n}=5\right.$, mean \pm SEM). ${ }^{\text {abcde }}$ Values with different superscripts along the same column for each parameter are significantly different $(\mathrm{P}<0.05)$. DA; diabetic animal, G6PDH; glucose-6-phosphate dehydrogenase

most profound influence that compared favourably well with that of the normal control group (Table 2). Similarly, the respective elevation and decrease in the hepatic activities of $\alpha$-amylase and G6PDH of the diabetic control animals was significantly and concentration-dependently reversed in PSAE-administered groups. Although, PSAE at the highest tested dose only compared with metformin on regulating the activity of $\mathrm{G} 6 \mathrm{PDH}$, it potentiated $\alpha$-amylase modulatory effect that competed well with both the metformin-treated animals at the lowest tested dose and normal control (Table 2).

Observable from Table 3 are the impacts of PSAE administrations on the hepatic antioxidant level and lipid peroxidation product of the animals. CAT and SOD activities were significantly $(p<0.05)$ induced by the extract in a dose-dependent pattern. The inductions markedly $(p<0.05)$ reversed the observed STZ-induced attenuation in the enzymes' activities in the diabetic control rats and the effect compared favorably with metformin. Similarly, the STZ-mediated reduction in GSH level and the increased MDA concentration in the diabetic control rats were significantly reversed in PSAE-treated animals (Table 3). 
Table 3: Effect of aqueous stem bark extract of $P$. suberosa on hepatic antioxidant systems and lipid peroxidation product (MDA) in diabetic rats.

\begin{tabular}{ccccc}
\hline & \multicolumn{2}{c}{$\mu \mathrm{mol} / \mathrm{min} / \mathrm{mg}$ protein } & \multicolumn{2}{c}{$\mu \mathrm{mol} / \mathrm{g}$ tissue } \\
Treatments & SOD & CAT & GSH & MDA \\
\hline Normal control & $50.52 \pm$ & $36.69 \pm$ & $40.13 \pm$ & $3.55 \pm$ \\
& $0.06^{\mathrm{a}}$ & $0.05^{\mathrm{a}}$ & $0.07^{\mathrm{a}}$ & $0.01^{\mathrm{a}}$ \\
& $12.82 \pm$ & $10.09 \pm$ & $10.62 \pm$ & $8.96 \pm$ \\
Diabetic control (DA) & $0.04^{\mathrm{b}}$ & $0.03^{\mathrm{b}}$ & $0.06^{\mathrm{b}}$ & $0.08^{\mathrm{b}}$ \\
& $56.62 \pm$ & $35.32 \pm$ & $29.35 \pm$ & $2.99 \pm$ \\
DA + Met. & $0.01^{\mathrm{c}}$ & $0.05^{\mathrm{a}}$ & $0.05^{\mathrm{c}}$ & $0.02^{\mathrm{a}}$ \\
(14.2 $\mathrm{mg} / \mathrm{kg}$ b.w.) & $48.32 \pm$ & $30.35 \pm$ & $28.62 \pm$ & $3.10 \pm$ \\
DA + 50 mg/kg b.w. & $0.03^{\mathrm{d}}$ & $0.07^{\mathrm{c}}$ & $0.02^{\mathrm{c}}$ & $0.01^{\mathrm{a}}$ \\
extract & $56.38 \pm$ & $30.31 \pm$ & $33.19 \pm$ & $3.09 \pm$ \\
DA + 100 mg/kg b.w. & $0.04^{\mathrm{a}}$ & $0.6^{\mathrm{c}}$ & $0.02^{\mathrm{d}}$ & $0.03^{\mathrm{a}}$ \\
extract & $56.59 \pm$ & $36.62 \pm$ & $38.62 \pm$ & $3.21 \pm$ \\
DA + 200 mg/kg b.w. & $0.02^{\mathrm{a}}$ & $0.05^{\mathrm{a}}$ & $0.07^{\mathrm{a}}$ & $0.08^{\mathrm{a}}$ \\
extract & & & &
\end{tabular}

$\left(\mathrm{n}=5\right.$, mean \pm SEM). ${ }^{\text {abcd } V a l u e s ~ w i t h ~ d i f f e r e n t ~ s u p e r s c r i p t s ~ a l o n g ~ t h e ~ s a m e ~}$ column for each parameter are significantly different $(\mathrm{P}<0.05)$. DA; diabetic animal. SOD; superoxide dismutase, CAT; catalase, GSH; glutathione (reduced), MDA; malondialdehyde

Table 4: In vitro antioxidant properties of aqueous stem bark extract of P. suberosa.

\begin{tabular}{ccccc}
\multirow{2}{*}{ Treatment } & \multicolumn{2}{c}{ DPPH } & \multicolumn{2}{c}{$\mathrm{H}_{2} \mathrm{O}_{2}$} \\
\cline { 2 - 5 } & $\mathrm{IC}_{50}(\mu \mathrm{g} / \mathrm{mL})$ & $\mathrm{R}^{2}$ & $\mathrm{IC}_{50}(\mu \mathrm{g} / \mathrm{mL})$ & $\mathrm{R}^{2}$ \\
\hline Extract & $2.06 \pm 0.02$ & 0.9245 & $0.73 \pm 0.01$ & 0.9682 \\
Vitamin C & $1.99 \pm 0.01$ & 0.9732 & $0.75 \pm 0.03$ & 0.9188 \\
\hline
\end{tabular}

$(\mathrm{n}=3$, mean \pm SEM $)$

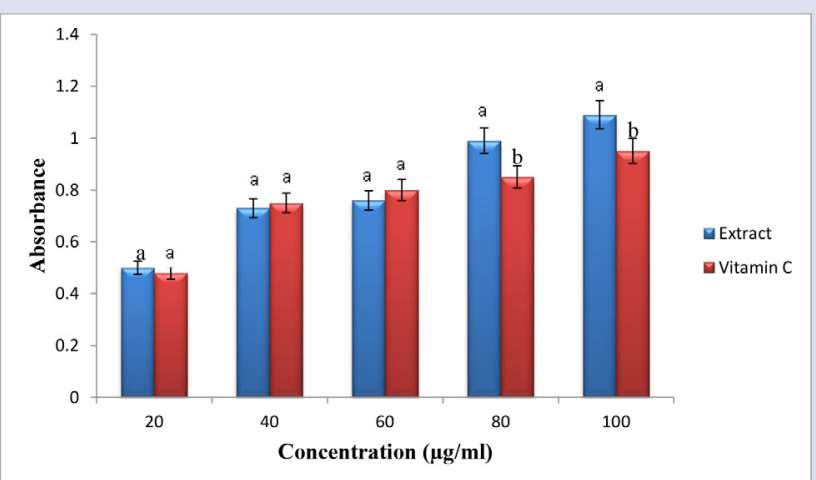

Figure 2: Reducing power effect of aqueous stem bark extract of P. suberosa $(n=3$, mean $\pm S E M)$. Bars with different superscripts for the parameter are significantly different $(p<0.05)$.

Table 4 and Figure 2 show the antioxidant properties of PSAE in vitro. Judging by the $\mathrm{IC}_{50}$ value of $2.06 \mu \mathrm{g} / \mathrm{mL}$ for PSAE when compared with vitamin $\mathrm{C}(1.99 \mu \mathrm{g} / \mathrm{mL})$, the extract scavenged the radicals formed with marked effect elicited on DPPH radicals. Also, compared with vitamin C $\left(\mathrm{IC}_{50} 0.75 \mu \mathrm{g} / \mathrm{mL}\right.$ ), PSAE $\left(\mathrm{IC}_{50} 0.73 \mu \mathrm{g} / \mathrm{mL}\right.$ ) remarkably scavenged $\mathrm{H}_{2} \mathrm{O}_{2}$ radical (Table 4). Although, the reducing power potential of the extract on ferric ion compared well with that of vitamin $\mathrm{C}$ at lower concentrations, better effects were evident at the higher doses investigated (Figure 2).
Table 5: Phytoconstituents of aqueous stem bark extract of $P$. suberosa.

\begin{tabular}{ccccc}
\hline Peak & RT (min) & \% AP & MF & Nomenclature \\
\hline 1 & 1.43 & 2.23 & $\mathrm{C}_{30} \mathrm{H}_{8} \mathrm{O}_{3}$ & Ursolate \\
2 & 1.67 & 1.50 & $\mathrm{C}_{17} \mathrm{H}_{26} \mathrm{O}_{4}$ & Gingerol \\
3 & 1.87 & 2.00 & $\mathrm{C}_{16} \mathrm{H}_{12} \mathrm{~N}_{2}$ & Cryptolepine \\
4 & 2.15 & 1.22 & $\mathrm{C}_{30} \mathrm{H}_{48} \mathrm{O}_{3}$ & Oleanolate \\
5 & 5.07 & 4.88 & $\mathrm{C}_{15} \mathrm{H}_{10} \mathrm{O}_{6}$ & Luteolin \\
6 & 5.82 & 1.49 & $\mathrm{C}_{15} \mathrm{H}_{10} \mathrm{O}_{6}$ & Kaempferol \\
7 & 6.20 & 1.66 & $\mathrm{C}_{15} \mathrm{H}_{10} \mathrm{O}_{5}$ & Apigenin \\
8 & 6.57 & 3.51 & $\mathrm{C}_{11} \mathrm{H}_{7} \mathrm{NO}_{3}$ & Furoquinoline \\
9 & 7.80 & 67.36 & $\mathrm{C}_{36} \mathrm{H}_{58} \mathrm{O}_{11}$ & Arjunglucoside \\
10 & 9.58 & 7.42 & $\mathrm{C}_{15} \mathrm{H}_{12} \mathrm{O}_{7}$ & Taxifolin \\
11 & 9.85 & 3.72 & $\mathrm{C}_{33} \mathrm{H}_{40} \mathrm{~N}_{2} \mathrm{O}_{9}$ & Reserpine \\
12 & 10.23 & 3.02 & $\mathrm{C}_{20} \mathrm{H}_{18} \mathrm{NO}_{4}^{+}$ & Berberine \\
\hline
\end{tabular}

$\mathrm{RT}=$ retention time, $\mathrm{AP}=$ area peak, $\mathrm{MF}=$ molecular formula

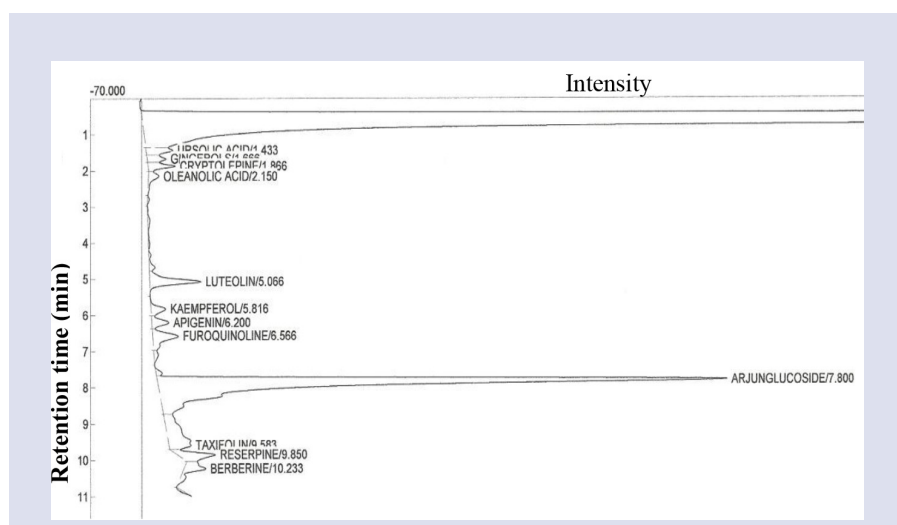

Figure 3: GCMS chromatogram of aqueous stem bark extract of P. suberosa.

The data from phytoconstituent analysis of PSAE using GC-MS showed that arjunglucoside $(67.36 \%)$, taxifolin $(7.42 \%)$, luteolin $(4.88 \%)$, reserpine $(3.72 \%)$, furoquinoline (3.51\%), berberine (3.02\%), ursolate $(2.23 \%)$ and cryptolepine $(2.00 \%)$ are the main phytonutrients in PSAE (Table 5, Figure 3).

\section{DISCUSSION}

Sustained hyperglycaemia is a characteristic feature of diabetes. In this study, the tending towards normalcy of the concentration of blood glucose in the extract-treated animals over the 15 days administration period is a probable indication of the significant hypoglycemic effect of PSAE.

Besides hyperglycemia, alteration in the lipid profile is an obvious occurrence in the diabetic state. For instance, the serum level of TC is often increased in diabetic state and such a rise is a potential indicator for coronary heart disease. This elevated serum level of TC during diabetes is attributable to either the increased hepatic activity of 3-hydroxyl 3-methylglutaryl co-enzyme A reductase or increased free fatty acids mobilization from the stores, since insulin inhibits the hormone sensitive lipase. ${ }^{34}$ Similarly, while an elevated TG level is a risk factor for heart related disorders, increase in the concentrations of LDL-C and TC with 
corresponding reduction in HDL-C as normally observed in diabetes are closely linked with inherent risk of myocardial infarction. ${ }^{35}$ In this study, treatments with PSAE was not only able to reduce the concentrations of LDL-C, TG and TC but also markedly improve the serum concentrations of HDL-C in the diabetic animals to near normalcy when compared with the diabetic control animals. While the effect of PSAE on the reduction of TC could be attributed to the reduced activity of 3-hydroxyl 3-methylglutaryl co-enzyme A reductase and increased bile acid excretion, the overall modulations in the lipid profile as evidently elicited by PSAE could be suggestive of its capability to protect the myocardial membrane, thereby proving to be effective in reducing the risks of cardiovascular diseases. Such significant improvement in the lipid profile could be linked to the anti-hyperlipidemic agents in PSAE. The observations on the lipid parameters in this study are consistent with previous reports, ${ }^{36,37}$ where normalizations of HDL-C, LDL-C, TG and TC in STZ-challenged animals were attributed to treatment with extracts of $C$. longa, A. augusta and G. biloba, respectively.

At any given time, the glycogen level in the system is a pointer to insulin activity. Intracellular glycogen assembly is facilitated by insulin under the respective inhibitory and stimulatory roles of glycogen phosphorylase and glycogen synthase. ${ }^{38}$ Since STZ inflicts pathological damage on the insulin-producing $\beta$-cells, it may be logically inferred that the significantly reduced hepatic glycogen concentration in the diabetic animals in this study may be due to either insufficient or total lack of insulin to stimulate glucose-glycogen conversion. The consequence of this is the abnormally increased concentrations of hepatic glucose in the untreated diabetic animals that contributed to sustained hyperglycaemia as observed in this study. However, the significantly modulated glycogen and glucose levels towards normalcy subsequent to treatment with PSAE may be indicative of its anti-hyperglycaemic potential. This might have involved concomitant stimulation and inhibition of the specific activities of glycogen synthase and glycogen phosphorylase, respectively. Similar submissions on the effects of plant extracts on the hepatic levels of glucose and glycogen have also been reported. ${ }^{39,40}$

Of the carbohydrates-metabolizing enzymes, $\alpha$-amylase is an important pharmacological target in the management of DM. ${ }^{41}$ It facilitates hydrolysis of starch to glucose with consequential increase in the systemic concentration of glucose. This increased hyperglycaemia may constitute a crucial risk factor for microvascular and macrovascular complications development as usually the case in DM. ${ }^{42}$ Hence, inhibition of this enzyme will delay glucose absorption and moderates postprandial blood glucose level. ${ }^{43}$ In the pentose phosphate pathway, the enzyme G6PDH is implicated in extra-mitochondrial NADPH production through regulation of the committed step involving formation of 6-phosphogluconate from glucose-6-phosphate. Its reduced activity is inimical to carbohydrate metabolism with an overall effect manifesting as hyperglycaemia. As observed in this study, PSAE had marked inhibitory effect on the specific activity of $\alpha$-amylase and this is therapeutically significant in regulating the rate of starch hydrolysis to free glucose. This observation may imply that PSAE is enriches with phytoconstituents that can effectively associate with the 3-dimensional structure of the enzyme to potentiate their inhibitory effect. Unlike the inhibitory influence of PSAE on the activity of $\alpha$-amylase, the significantly enhanced specific G6PDH activity in PSAEadministered animals may signify glucose lowering effect of PSAE. This might have been achieved through facilitated channelling of glucose into other routes like glycolytic pathway rather than pentose phosphate pathway in an attempt to ameliorate hyperglycaemia, thus stimulating G6PDH activity. This concept is further supported by the observed reduction in the hepatic glucose levels of the PSAE-administered animals over the 15-day experimental period. Our findings agree with earlier submissions. ${ }^{40,44}$ The authors opined that improvement in the specific activities of $\alpha$-amylase and G6PDH following STZ intoxication in rats was due to the respective normoglycaemic effects of sodium molybdate and $A$. ringens root extracts.

Apart from the increasing evidence from experimental, epidemiological and clinical data that, reactive oxygen species (ROS) are involved in the pathogenesis of DM and its complications, other critical events such as autooxidation of glucose, non-enzymatic protein glycosylation, alteration in antioxidant enzymes' (SOD, CAT) status, impaired GSH metabolism and lipid peroxides formation (MDA) have also been implicated. The present findings indicate significant reduction in GSH, SOD and CAT in the diabetic rats and their subsequent improvement by PSAE treatment. GSH is multitasked in antioxidant defense system with a direct primary role as ROS scavenger coupled with significant involvement in peroxide detoxification. ${ }^{45}$ The decreased GSH level and the activities of CAT and SOD in the untreated diabetic animals could depict response to increased $\mathrm{H}_{2} \mathrm{O}_{2}$ and $\mathrm{O}_{2}$ production resulting from glucose autooxidation. These non-enzymic and enzymic antioxidants work synergistically in maintaining optimal concentrations of $\mathrm{O}_{2}$ and $\mathrm{H}_{2} \mathrm{O}_{2}$ by enhancing prompt ROS dismutation and annihilating hydroperoxides and organic peroxides produced from STZ treatment. ${ }^{46}$ The observed increases in the enzymes' activities and GSH level in PSAE-treated rats may be indicative of the antioxidant activity of PSAE. Furthermore, the increased levels of MDA (a lipid peroxidation product) as evident from the untreated diabetic groups in this study could be correlated with intensified ROS autooxidation of the hepatic membranal lipids. Such observation on the elevated concentrations of lipid peroxide products has been previously reported and attributed to STZ-induced hyperglycaemia in experimental animals. ${ }^{47}$ Conversely, treatment with the extract significantly reduced MDA levels and this may be indicative of the antioxidant activity of PSAE. It may also suggest that the extract is rich in phytoconstituents of antioxidant significance that could effectively boost the antioxidant status of the animals, thereby mitigating STZ-mediated oxidative stress. In addition to further supporting that PSAE offered significant level of antioxidant and antidiabetic action at the investigated doses, this observation is also consistent with the report of Ravi et al..$^{48}$ when evaluating the hypoglycaemic potential of E. jambolana seed kernel in STZ-challenged animals.

In the same vein, the observed marked in vitro anti-radical activities of the extract as revealed by its $\mathrm{IC}_{50}$ values relative to that of vitamin $\mathrm{C}$ (reference standard) is another tenable fact supporting its antioxidant potential. Such effect as elicited by PSAE against the investigated radicals is informative its capability to stall ROS cascade reactions associated with diabetes and its complications. This might have been facilitated by the ability of the phytonutrients in PSAE to either donate electron/H atom to incapacitate ROS or compete with $\mathrm{O}_{2}$ to react with $\mathrm{NO}$ to inhibit $\mathrm{NO}_{3}^{*}$ formation and as such complementing the in vivo antioxidant activities of PSAE.

Put together, the pharmacological properties shown by PSAE in the present study could be closely associated with its phytonutrients with well-defined antioxidant potential as revealed by the GC-MS results. Besides the antioxidant potential of these compounds, the significant antidiabetic activities of arjunglucosides, furoquinoline, ursolate, gingerol and kaempferol to stimulate regeneration of pancreatic $\beta$-cells have been well established. ${ }^{49-53}$ The marked beneficial role of taxifolin, cryptolepine and reserpine in inhibiting activities of carbohydrate metabolizing enzymes and preserving $\beta$-cell function through oxidative stress obliteration have also been documented. ${ }^{54-56}$ Furthermore, while the improved hemostatic imbalance and glycemic control, attenuated lipid peroxidation and ameliorated inflammatory and oxidative stress in diabetic animals have been linked with antidiabetic attributes of luteolin, gingerol and ursolate, ${ }^{49,53,57}$ berberine and kaempferol have been opined to elicit antidiabetic influence 


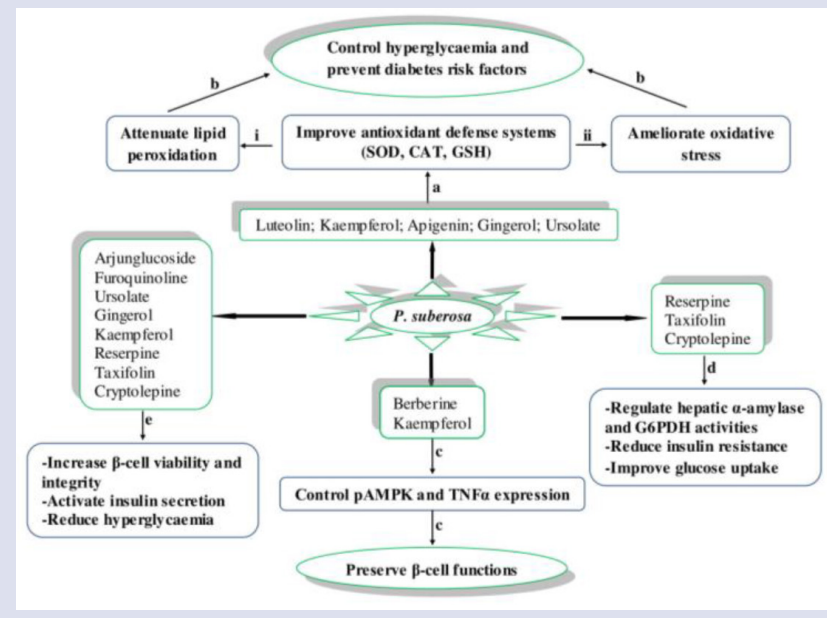

Figure 4: A scheme of the tentative mechanisms of antidiabetic actions of aqueous stem bark extract of $P$. suberosa in Wistar rats. $P$. suberosa is endowed with diverse phytonutrients which aid (a) induction and optimization of SOD and CAT activities that eventually improve GSH content, (i) arrest lipid peroxidation and (ii) effectively halt oxidative stress. These events will ultimately (b) prevent hyperglycaemia and abort the likelihood of occurrence of diabetes complications. The constituents may also facilitate (c) glucose-mediated insulin secretion and protection of $\beta$-cells against oxidative damage via regulation of PAMPK and TNFa expression, (d) effective regulation of carbohydrate enzymes' activities, reduce insulin resistance and subsequently improve glucose uptake, (e) increase in the number of pancreatic islets that will enhance improved glucose tolerance, stimulate insulin secretion and ultimately attenuate high blood glucose level. SOD; superoxide dismutase, CAT; catalase, GSH; reduced glutathione, PAMPK; phosphorylated 5' AMP-activated protein kinase, TNFa; tumor necrosis factor alpha, G6PDH; glucose-6-phosphate dehydrogenase.

through the respective enhanced and reduced expressions of phosphorylated 5' AMP-activated protein kinase (pAMPK) and tumor necrosis factor alpha (TNFa) in kidneys of mice..$^{52,58}$

Considering the foregoing, a probable mechanism of antioxidant and hypoglycaemic actions of PASE could be conceptualized (Figure 4). This may be proposed to potentiate hypoglycaemia through regulatory influence on carbohydrate metabolizing enzymes ( $\alpha$-amylase, G6PDH) that would facilitate delay in carbohydrate digestion and reduce insulin resistance. The antioxidant constituents of the extract may facilitate sugar-mediated insulin secretion coupled with conferring marked protection on the pancreatic $\beta$-cells against oxidative onslaughts by controlling expressions of pAMPK and TNFa in the kidneys. Such effect would subsequently contribute to the regulation of glucose-induced insulin secretion, modulate the specific activities of hepatic carbohydrate enzymes and increase the number of pancreatic islets that will aid improved glucose tolerance. Additionally, luteolin and other antioxidant constituents in PSAE may offer further protection against oxidative damage and by so doing facilitate induction and optimization of SOD and CAT that would ultimately increase the level of GSH and effectively annihilate the deleterious effects of ROS (Figure 4).

\section{CONCLUSION}

Based on the available data presented in this study, it may be logically concluded that the 15-day administration of aqueous stem bark extract of $P$. suberosa elicited marked hypoglycemic potential in STZ-challenged diabetic animals. The data also divulged the beneficial attributes of the extract in boosting antioxidant defense systems and improving the lipid metabolism imbalance experienced during diabetes. Beside these attributes, PSAE could also protect liver impairment due to diabetes and as such stands a promising chance as a viable new lead candidate to manage and treat diabetes and its accompanying complications.

\section{ACKNOWLEDGEMENT}

Non.

\section{CONFLICT OF INTEREST}

The authors declare no conflict of interests.

\section{ABBREVIATIONS}

STZ: Streptozotocin; PSAE: Pteleopsis suberosa Aqueous Extract; GC-MS: Gas Chromatography-Mass Spectrometer; PS: Pteleopsis suberosa; DM: Diabetes Mellitus; IDF: International Diabetes Federation; DPPH: 2,2-diphenyl-1-picrylhydrazyl; HDL-C: High Density Lipoprotein Cholesterol; LDL-C: Low Density Lipoprotein Cholesterol; TC: Total Cholesterol; TG: Triglycerides; EDTA: Ethylenediaminetetraacetic acid; G6PDH: Glucose-6-phosphate dehydrogenase; MDA: Malondialdehyde; CAT: Catalase; SOD: Superoxide Dismutase; GSH: Glutathione (reduced); SEM: Standard Error of the Mean; ROS: Reactive Oxygen Species; pAMPK: Phosphorylated 5' AMP-activated protein kinase; TNFa: Tumor Necrosis Factor alpha.

\section{REFERENCES}

1. De Pasquale R, Germanò MP, Keita A, Sanogo R, lauk L. Antiulcer activity of Pteleopsis suberosa. Journal of Ethnopharmacology. 1995;47(1):55-8.

2. Bhavani PK, Aik WT, Basil DR. Pharmacology of traditional herbal medicines and their active principles used in the treatment of peptic ulcer, diarrhoea and inflammatory bowel disease. New Advances in Basic Clinical Gastroenterology. 2012;14:297-310.

3. Akintunde JK, Babaita AK. Effect of PUFAs from Pteleopsis suberosa stem bark on androgenic enzymes, cellular ATP and prostatic acid phosphatase in mercury chloride - exposed rat. Middle East Fertility Society Journal. 2017;22(3):211-8.

4. Lagnika L, Fantodji MHT, Sanni A. Phytochemical study and antibacterial, antifungal and antioxidant properties of Bridelia ferruginea and Pteleopsis suberosa. International Journal of Pharmaceutical Science Research. 2012;3(7):2130-6.

5. Khan SE, Hull RL, Utzschneider KM. Mechanisms linking obesity to insulin resistance and type 2 diabetes. Nature. 2006;444 (7121):840-6.

6. Bakirel T, Bakirel U, Keles OU, Ulgen SG, Yardibi H. In vivo assessment of antidiabetic and antioxidant activities of rosemary (Rosmarinus officinalis) in alloxan diabetic rabbits. Journal of Ethnopharmacology. 2008;16(1):64-73.

7. Oh YS. Plant-derived compounds targeting pancreatic beta cells for the treatment of diabetes. Evidence-Based Complementary and Alternative Medicine. $2015 ; 12$.

8. Abdulazeez SS, Ponnusam P. Antioxidant and hypoglycemic activity of strawberry fruit extracts against alloxan induced diabetes in rats. Pakistan Journal of Pharmaceutical Sciences. 2016;29:255-60.

9. Shaw JE, Sicree RA, Zimmet PZ. Global estimates of the prevalence of diabetes for 2010 and 2030. Diabetes Research and Clinical Practice. 2010;87(1):4-14.

10. International Diabetes Federation (IDF) Diabetes Atlas, 2012. $5^{\text {th }}$ edition update, Brussels, International Diabetes Federation. Accessed May 2017.

11. Gull MZ, Bhakshu LM, Ahmad F, Kondapi AK, Qureshi IA, Ghazi IA. Evaluation of Abelmoschus moschatus extracts for antioxidant, free radical scavenging, antimicrobial and antiproliferative activities using in vitro assays. BMC Complementary and Alternative Medicine. 2011;11(1):64.

12. Ghosh S, Derle A, Ahire M, More P, Jagtap S, Phadatare SD, et al. Phytochemical analysis and free radical scavenging activity of medicinal plants Gnidia glauca and Dioscorea bulbifera. PLoS ONE. 2013;8(12):e82529.

13. Mendes MF, David I, Bogle L. Evaluation of the effects and mechanisms of bioactive components present in hypoglycemic plants. International Journal of Chemical and Biomolecular Science. 2015;1(3):167-78.

14. Sabiu S, Ajani EO, Sunmonu TO, Ashafa AOT. Kinetics of modulatory role of Cyperus esculentus $L$. on the specific activity of key carbohydrate metabolizing enzymes. African Journal of Traditional Complementary and Alternative Medicine. $2017 ; 14(4): 46-53$ 
15. Ray A, Gulati K, Anand R. Stress, adaptogens and their evaluation: An overview. Journal of Pharmacological Report. 2016;1(110):2.

16. Karou SD, Tchacondo T, Tchibozo MAD, Abdoul-Rahaman S, Anani K, Koudouvo K, et al. Ethnobotanical study of medicinal plants used in the management of diabetes mellitus and hypertension in the Central Region of Togo. Pharmaceutical Biology. 2011;49(12):1286-97

17. Borokini TI, Ighere DA, Clement M, Ajiboye TO, Alowonle AA. Ethnobiological survey of traditional medicine practice for the treatment of piles and diabetes mellitus in Oyo State. Journal of Medicinal Plants Studies. 2013;1(5):30-40.

18. Lawin IF, Lalèyè OAF, Agbani OP, Assogbadjo AE. Ethnobotanical assessment of the plant species used in the treatment of diabetes in the Sudano-Guinean zone of Benin. Journal of Animal and Plant Sciences. 2015;26(1):4108-23

19. National Institute of Health (NIH). Care and Use of Laboratory Animals. National Institute of Health Publication. 1985;85.

20. National Research Council (NRC). Guide for the Care and Use of Laboratory Animals: $8^{\text {th }} \mathrm{Ed}$, in: Guide for the Care and Use of Laboratory Animals. National Research Council. 2011;118.

21. Bell RH, Hye JRJ. Animal models of diabetes mellitus: physiology and pathology Journal of Surgery Research. 1983;35(5):433-60.

22. Bauer $P$, Brannath $W$, Posch $M$. Multiple testing for identifying effective and safe treatments. Biometry Journal. 2001;43(5):605-16.

23. Morales MA, Jabbagy AJ, Terenizi HR. Mutations affecting accumulation of glycogen. Neurospora News Letters. 1973;30:24-5

24. Barham D, Trinder T. An improved colour reagent for the determination of blood glucose by the oxidase system. Analyst. 1972;97(1151):142-5.

25. Lohr GW, Waller HD. Glucose-6-phosphate dehydrogenase. Method of enzymatic analysis, third ed.Varlag Chemie, Wehnheim. 1974;636.

26. McCue P, Vattem D, Shetty K. Inhibitory effect of clonal oregano extracts against porcine pancreatic amylase in vitro. Asian Pacific Journal of Clinical Nutrition. 2004;13(4):401-8.

27. Reilly CA, Aust SD. Measurement of lipid peroxidation. Current Protocol in Toxicology. $2001 ; 2: 2-4$

28. Aebi H. Catalase in vitro. Methods in Enzymology. 1984;105:121-6.

29. Marklund S, Marklund G. Involvement of superoxide anion radical in the autooxidation of pyrogallol and a convenient assay for superoxide dismutase. European Journal of Biochemistry. 1974;47(3):469-74.

30. Ellman GL. Tissue sulfhydryl groups. Archives of Biochemistry and Biophysics. $1959 ; 82(2): 70-7$

31. Oyaizu M. Studies on products of browning reaction: antioxidative activities of product of browning reaction pre- pared from glucosamine. Japanese Journal of Nutrition. 1986;44(6):307-15.

32. Ruch RJ, Cheng SJ, Klaunig JE. Prevention of cytotoxicity and inhibition of intercellular communication by antioxidant catechins isolated from Chinese green tea. Carcinogen. 1989;10(6):1003-8.

33. Turkoglu A, Duru ME, Mercan N, Kivrak I, Gezer K. Antioxidant and antimicrobial activities of Laetiporus sulphureus (Bull). Food Chemistry. 2007:101(1):267-73.

34. Al-Shamaony L, Al-Khazraji SM, Twaij HAA. Hypoglycaemic effect of Artemisia herba alba. II. Effect of a valuable extract on some blood parameters in diabetic animals. Journal of Ethnopharmacology. 1994;43(3):167-71.

35. Mediene-Benchekor S, Brousseau T, Richard F, Benhamamouch S, Amouyel P Blood lipid concentrations and risk of myocardial infarction. The Lancet 2001;358(9287):1064-5.

36. Hussain HE. Hypoglycemic, hypolipidemic and antioxidant properties of combination of curcumin from Curcuma longa, Linn. and partially purified product from Abroma augusta, Linn. in streptozotocin induced diabetes. Indian Journal of Clinical Biochemistry. 2002;17(2):33-43.

37. Cheng D, Liang B, Ling Y. Antihyperglycemic effect of Ginkgo biloba extract in streptozotocin induced diabetes rats. Biomedical Research International. 2013:162-724

38. Malini P, Kanchana G, Rajadurai M. Antibiabetic efficacy of ellagic acid in streptozotocin-induced diabetes mellitus in albino wistar rats. Asian Journal of Pharmaceutical and Clinical Research. 2011;4(3):124-8.

39. Anusooriya P, Malarvizhi D, Kanniappan VG, Devaki K. Antioxidant and antidiabetic effect of aqueous fruit extract of Passiflora ligularis Juss. on streptozotocin induced diabetic rats. International Scholarly Research Notices. 2014;10. Article ID 130342
40. Sulyman A, Akolade JO, Sabiu SA, Aladodo RA. Antidiabetic potentials of ethanolic extract of Aristolochia ringens (Vahl.) roots. Journal of Ethnopharmacology. 2016;182:122-8

41. Krentz AJ, Baile CJ. Oral antidiabetic agents: Current role in type 2 diabetes mellitus. Drugs. 2005;65(3):385-411.

42. Kim JS, Kwon CS, Son KH. Inhibition of alpha glucosidase and amylase by luteolin, a flavonoid. Biosciences, Biotechnology and Biochemistry. 2000;64(11):2458-61.

43. Sabiu S, Ashafa AOT. Membrane stabilization and kinetics of carbohydrate metabolizing enzymes ( $\alpha$-amylase and $\alpha$-glucosidase) inhibitory potentials of Eucalyptus obliqua L. Her. (Myrtaceae) Blakely ethanolic leaf extract: An in vitro assessment. South African Journal of Botany. 2016;105:264-9.

44. Panneerselvam RS, Govindaswamy S. Effect of sodium molybdate on carbohydrate metabolizing enzymes in alloxan induced diabetic rats. Journal of Nutrition and Biochemistry. 2002;13(1):21-6.

45. Sabiu S, O'Neil FH, Ashafa AOT. Membrane stabilization and detoxification of acetaminophen-mediated oxidative onslaughts in the kidneys of Wistar rats by standardized fraction of Zea mays L. (Poaceae), Stigma maydis. EvidenceBased Complementary Alternative Medicine. 2016;14. Article ID 2046298.

46. Pari L, Latha M. Protective role of Scoparia dulcis plant extract on brain antioxidant status and lipid peroxidation in STZ diabetic male Wistar rats. BMC Complementary and Alternative Medicine. 2004;4(1):16.

47. Maritim AC, Sanders RA, Watkins JB. Diabetes, oxidative stress and antioxidants: a review. Journal of Biochemistry and Molecular Toxicology. 2003;17(1):24-38

48. Ravi K, Sivagnanam K, Subramanian S. Anti-diabetic activity of Eugenia jambolana seed kernels on streptozotocin induced diabetic rats. Journal of Medicinal Food. 2004;7(2):187-91.

49. Singab ANB, El-Beshbishy HA, Yonekawa M, Nomura T, Fukai T. Hypoglycemic effect of Egyptian Morus alba root bark extract: Effect on diabetes and lipid peroxidation of streptozotocin-induced diabetic rats. Journal of Ethnopharmacology. 2005;100(3):333-8.

50. Ahmed OM, Moneim AA, Yazid IA, Mahmoud AM. Antihyperglycemic, antihyperlipidemic and antioxidant effects and the probable mechanisms of action of Ruta graveolens infusion and rutin in nicotinamide streptozotocin-induced diabetic rats. Diabetologia Croatica. 2010;39(1):15-35.

51. Perveen K, Kahn R, Siddiqui WA. Antidiabetic effects afforded by Terminalia arjuna in high fat-feed and STZ-induced type 2 diabetic rats. International Journal of Diabetes Metabolism. 2011;19:23-33.

52. Alkhalidy $\mathrm{H}$, Moore $\mathrm{W}$, Zhang $\mathrm{Y}$, McMillan $\mathrm{R}$, Wang A, Ali M, et al. Small molecule kaempferol promotes insulin sensitivity and preserved pancreatic $\beta$-cell mass in middle-aged obese diabetic mice. Journal of Diabetes. 2015;14 Research Article ID 532984

53. Son MJ, Miura Y, Yagasaki K. Mechanisms for antidiabetic effect of gingerol in cultured cells and obese diabetic model mice. Cytotechnology. 2015;67(4):641-52.

54. Qureshi SA, Nawaz A, Udani SK, Azmi B. Hypoglycaemic and hypolipidemic activities of Rauwolfia serpentina in alloxan-induced diabetic rats. International Journal of Pharmacology. 2009;5(5):323-6.

55. Ajayi AF, Akhigbe RE, Adewumi OM, Okeleji LO, Mujaidu KB, Olaleye SB Effect of ethanolic extract of Cryptolepis sanguinolenta stem on in vivo and in vitro glucose absorption and transport: Mechanism of its antidiabetic activity. Indian Journal of Endocrinology Metabolism. 2012;16(I1):S91-S96.

56. Balamurugan $\mathrm{R}$, Vendan SE, Aravinthan A, Kim JH. Isolation and structura characterization of 2R, 3R taxifolin 3-O-rhamnoside from ethyl acetate extract of Hydnocarpus alpina and its hypoglycemic effect by attenuating hepatic key enzymes of glucose metabolism in streptozotocin-induced diabetic rats. Biochimie. 2015:111:70-81.

57. Zang Y, Igarashi K, LiY. Anti-diabetic effects of luteolin and luteolin-7-O-glucoside on KK-A(y) mice. Bioscience, Biotechnology and Biochemistry. 2016;80(8):1580-6.

58. Tian CM, Jiang $X$, Ouyang XX, Zhang YO, Xie WD. Berberine enhances antidiabetic effects and attenuates untoward effects of canagliflozin in streptozotocin-induced diabetic mice. Chinese Journal of Natural Medicine. 2016;14(7):518-26.

Cite this article: Aladodo AR, Sabiu S, Sulyman AO. Pteleopsis suberosa Engl. and Diels (Combretaceae) aqueous stem bark extract extenuates oxidative damage in streptozotocin-induced diabetic Wistar rats. Pharmacog J. 2019;11(1):183-90. 
GRAPHICAL ABSTRACT

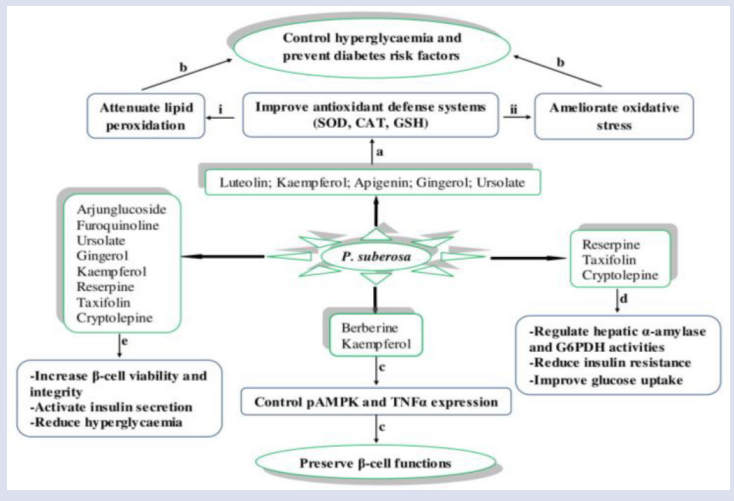

\section{SUMMARY}

- Anti-diabetic effect of $P$. suberosa was evaluated in vivo

- Its extract was tested on streptozotocin-induced oxidative damage in rats

- Antioxidant activity and GC-MS analysis of the extract were also evaluated

- The extract had concerted significant blood glucose lowering and antioxidant effects

- Its phytonutrients were the implicated adaptogenic compounds for the elicited effects

- The scheme for the tentative mechanisms of anti-diabetic actions of the extract was proposed 